\title{
What is a fault scarp?
}

Characteristics of fault-generated landforms can be sensitive indicators of the style and timing of tectonic activity. Because the definition of the term "fault scarp" varies among workers, a fault scarp is defined here as a tectonic landform coincident, or roughly coincident, with a fault plane that has dislocated the ground surface. The various types of fault scarps vary in morphology and extent, and they tell us about the style of near-surface deformation, the characteristics of the near-surface material, and the duration of faulting.

Geomorphic modification of fault scarps presents further classification of scarps, and the term "residual fault scarp" is preferred by the authors to describe all mature scarps from which the last remnants of the original tectonic surface have been removed by geomorphic modification. In contrast to the geomorphic modification of fault scarps in poorly consolidated sediments, which lack morphological characteristics related to the deformation processes, fault-scarp morphology in bedrock may be controlled either by geomorphic activity or by structural heterogeneity. Piedmont scarps in the western United States are compared to bedrock scarps in the Aegean region, where carbonate bedrock scarps may be underlain by belts and sheets of fault rocks that parallel the fault zone and vary in their resistance to erosion. Assessment of the degree of degradation of all scarps, including bedrock scarps, may provide a useful guide to the age of the scarp. (Ed.)

\section{Introduction}

The need to augment the instrumental and historical record of tectonic activity has, in the last decade, focused attention on paleoseismology - the identification and study of prehistoric earthquakes as determined from the geological and geomorphological record. Of great importance has been the recognition that the characteristics of faultgenerated landforms, such as fault scarps, can be sensitive indicators of the style and timing of tectonic activity within a region (Wallace, 1977). In tectonic geomorphology, the term "fault scarp" has been applied to a wide range of scarps that are more or less coincident with a fault plane on which recent motion has taken place. Such scarps range from small, ephemeral slopes created by a single increment of displacement to high bedrock escarpments that formed during repeated slip. The term "fault scarp" is used by some workers to describe only fresh scarps, whereas other workers, particularly those in tectonically inactive terranes such as the UK, apply it to degraded scarps or even faultline scarps. This article reviews the contrasting structural and morphological characteristics of fault scarps that were formed during recent tectonic activity, and we suggest some definitions of key terms.

\section{Fault-scarp studies}

In a study of young normal-fault scarps cutting Quaternary sediments in the Basin and Range province of the western USA, Wallace (1977) proposed that fault scarps possessing a steep, angular morphology were generally younger than scarps having a gentle, rounded morphology. This assessment was formalized later by Bucknam and Anderson (1979), who demonstrated empirically that the maximum scarp angle decreases with age and increases with scarp height. The recognition that certain elements of scarp profiles, such as scarp angle and scarp height, represent time-dependent criteria has allowed contrasting faultscarp populations to be discriminated and to have broad age categories assigned to them (for example, Holocene, late Pleistocene). More recently, fault-scarp studies have attempted to simulate mathematically the degradation of fault scarps in order to provide absolute age estimates (Nash, 1986).

In addition to providing information on the timing of tectonic activity within a region, fault-scarp studies have revealed much information concerning the spatial and temporal distribution of the faulting itself. Lateral changes in fault-scarp morphology along a fault zone, for example, are interpreted commonly as the surface expression of the deeper level segmentation of the fault zone (see Crone and Haller, 1991). Detailed investigations of historical fault breaks and fault-scarp stratigraphy have shown that many active faults rupture at relatively regular intervals, that they have similar magnitudes, and that they rupture along traces roughly coincident with those of previous events. Such studies form the basis of existing models of fault behavior.

\section{Fault scarps and fault-generated landforms}

A fault scarp is defined here as a tectonic landform coincident, or roughly coincident, with a fault plane that has dislocated the ground surface. Figure 1 illustrates examples of simple scarps related to single increments of slip. Different styles of fault motion create contrasting types of scarps, although some fault-generated landforms are morphologically indistinguishable from one another. Normal-fault scarps are generally the easiest to detect, even where they are not related to the primary fault on which motion occurred. For example. during the 1980 El Asnam (Algeria) magnitude 7.3 earthquake. the most prominent fault-generated landforms were normal-fault scarps that formed as a result of secondary stretching above a thrust-related topographic flexure (fig. 2) (King and Vita-Finzi, 1981). Conversely, reverse-fault scarps formed during the same event were variable in morphology and laterally discontinuous. In contrast to normal- and reverse-fault scarps that are best displayed where a nearly level surface is offset, scarps 


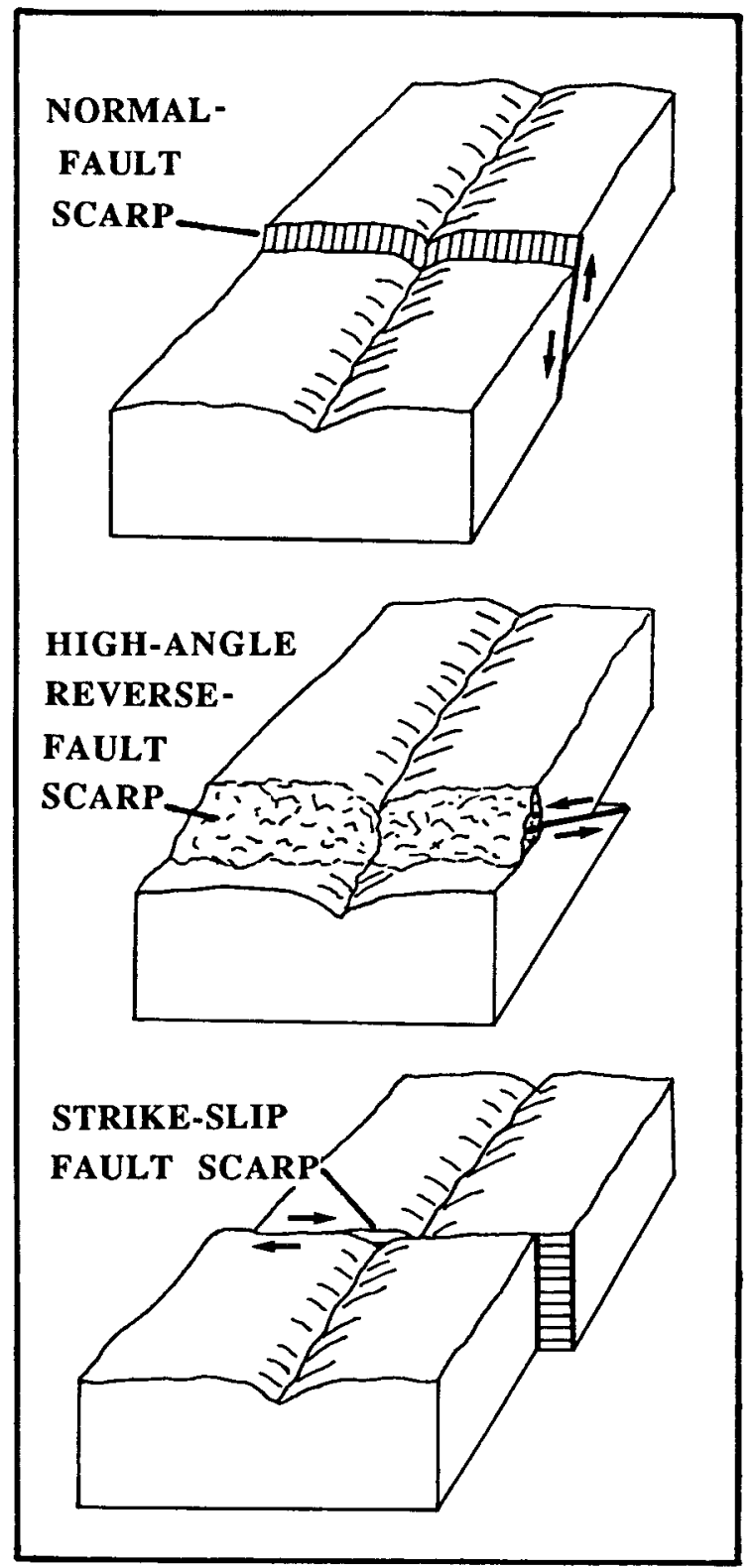

Figure 1.-Simple scarps related to single increments of slip on a newly propagated fault. Modified from Hancock (1988, fig. 9).

associated with strike-slip faulting are detected most readily where the fault trace crosses sloping ground (fig. 1).

The initial morphology of a fault scarp also is strongly influenced by the style of near-surface deformation. Studies of normal-fault scarps in the western USA have focused primarily on piedmont scarps - small faults cutting poorly consolidated Quaternary sediment deposited at the base of range fronts (Gilbert, 1928, p. 33). Where a piedmont scarp is the product of a single increment of motion, it commonly displays a characteristic morphology (fig. 3A) (Wallace, 1977) comprising a steep $\left(>50^{\circ}\right)$ free face, a moderately inclined $\left(30^{\circ}-40^{\circ}\right)$ debris slope, and a gently inclined $\left(5^{\circ}-10^{\circ}\right)$ wash slope. More commonly, however, the morphology of piedmont scarps is complicated either by nearsurface splay faults, which produce multiple scarps (fig. 3B), or by repeated displacements along the same fault, which form composite
NW

SE

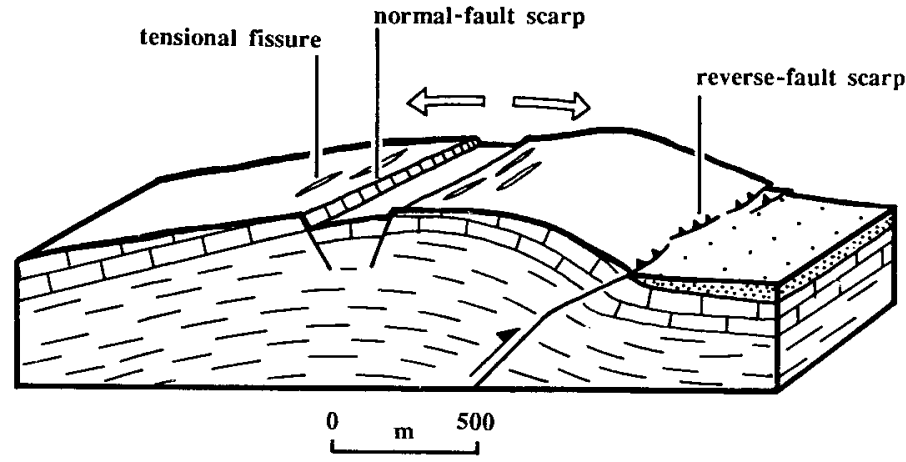

Figure 2.-Structure of the south-central part of the fault zone active during the $1980 \mathrm{El}$ Asnam (Algeria) earthquake. Although the main thrust was expressed as a series of discontinuous, poorly developed reverse-fault scarps, stretching (open arrows) in the hanging wall of the thrust resulted in the formation of clearly expressed normal-fault scarps and tensional fissures. Redrawn from Philip and Meghraoui (1983, fig. 15).

scarps (fig. 3C). The terminology of these features, however, is confused by references to multiple scarps as "branched fault scarps" (Cotton, 1949) and by references to composite scarps as "multipleevent scarps" (for example, Mayer, 1984), "multiple offset scarps" (Petersen, 1985), and "rejuvenated scarps" (McCalpin, 1987). In order to describe the situation where displacement is distributed across a number of overlapping en échelon fault strands, Cotton (1949) coined the term "splintered scarp" (fig. 3D).

Scarps formed by normal faulting are located commonly along preexisting faults that are coincident with the contact between bedrock in the footwall and Quaternary colluvial or alluvial sediment in the hanging wall (Crone and others, 1987). In some faulting events. however, the upward-propagating fault steepens toward the surface (Hancock and Barka, 1987) and forms fresh, steeply inclined to overhanging scarps in colluvium or alluvium. Such a tendency may lead to reverse faults being expressed as apparent normal-fault scarps and vice versa (Philip and Meghraoui, 1983). For example, the directions of opening vectors that were constructed from apparent reverse-fault scarps formed during the 1978 Thessaloníki (northern Greece) magnitude 6.1 earthquake showed extension. These directions indicated a slip vector comparable to that displayed by striae on bedrock normal faults reactivated during the same faulting event (fig. 4) (Mercier and others, 1983).

The shapes of fault scarps also are strongly influenced by the properties of the displaced rocks. Gordon (1971), for example, documented eight main fault-scarp types that accompanied reverse faulting during the 1968 Meckering (Australia) magnitude 6.9 earthquake. Where the near-surface material was strong, the reverse faulting occurred on a single slip plane to form a simple overhanging scarp that collapsed or was eroded back (fig. 1). Where the surface material was weak, however, internal warping resulted in the formation of a topographic flexure, here called a fold-limb scarp (fig. 5). Such scarps also have been referred to as "monoclinal scarps" (Cotton, 1950) and "fold scarps" (Matsuda and others, 1989). Although these scarps are comparable in morphology to normal-fault scarps, they differ from true fault scarps in that the scarp face corresponds to a dip slope (that is, a tilted or rotated erosional or depositional slope) (Thornbury, 1964). On a larger scale, fold-limb scarps are interpreted as the surface expression of blind thrusts, ahead of which deformation is accommodated by fault-propagation folds (Stein and Yeats, 1989). 
As repeated increments of normal- or reverse-fault motion take place, bedrock escarpments can form that are several hundred meters in height. Active fault-generated mountain fronts or range fronts are commonly linear mountain fronts that display triangular facets representing the ends of ridges that have been truncated by the rangebounding fault. Some range fronts, such as the Wasatch front in the eastern Basin and Range province of Utah, USA (fig. 6), exhibit several flights of triangular facets, which result in as tepped appearance that commonly is interpreted as reflecting punctuated uplift (Hamblin, 1976). Although stepped range fronts occur in other areas of active normal faulting, some of them in the Aegean region are products of distributed normal splay faulting (fig. 7A) (Stewart and Hancock, 1991). By contrast. where faulting is concentrated along a single fault plane, the resulting range front possesses a ramplike morphology.

Although the degree of linearity of range fronts in the Basin and Range province generally is regarded as a measure of their relative youthfulness (Bull and McFadden, 1977), sinuous mountain fronts are also characteristic of some areas of active tectonism. Cotton (1950), for example, has described active range fronts in New Zealand that display well-rounded fronts, which were formed by spur ridges being blunted by stream dissection at their base. Similarly, mountain fronts, such as the Salt Range in Pakistan, that mark the leading edges of emergent flat thrusts are commonly embayed (Yeats and Lillie, 1991). Although such escarpments rise above a sharp break in slope coincident with an emergent thrust-flat trace, the escarpment is not a true fault scarp but rather the margin of a thrust sheet, the leading edge of which has collapsed and been overridden (fig. 7B). We propose that such features be called thrust-front scarps in order to distinguish them from thrust-fault scarps. Scarps associated with strike-slip faults are mainly the result of the juxtaposition of formerly separate areas of different height (fig. 7C).

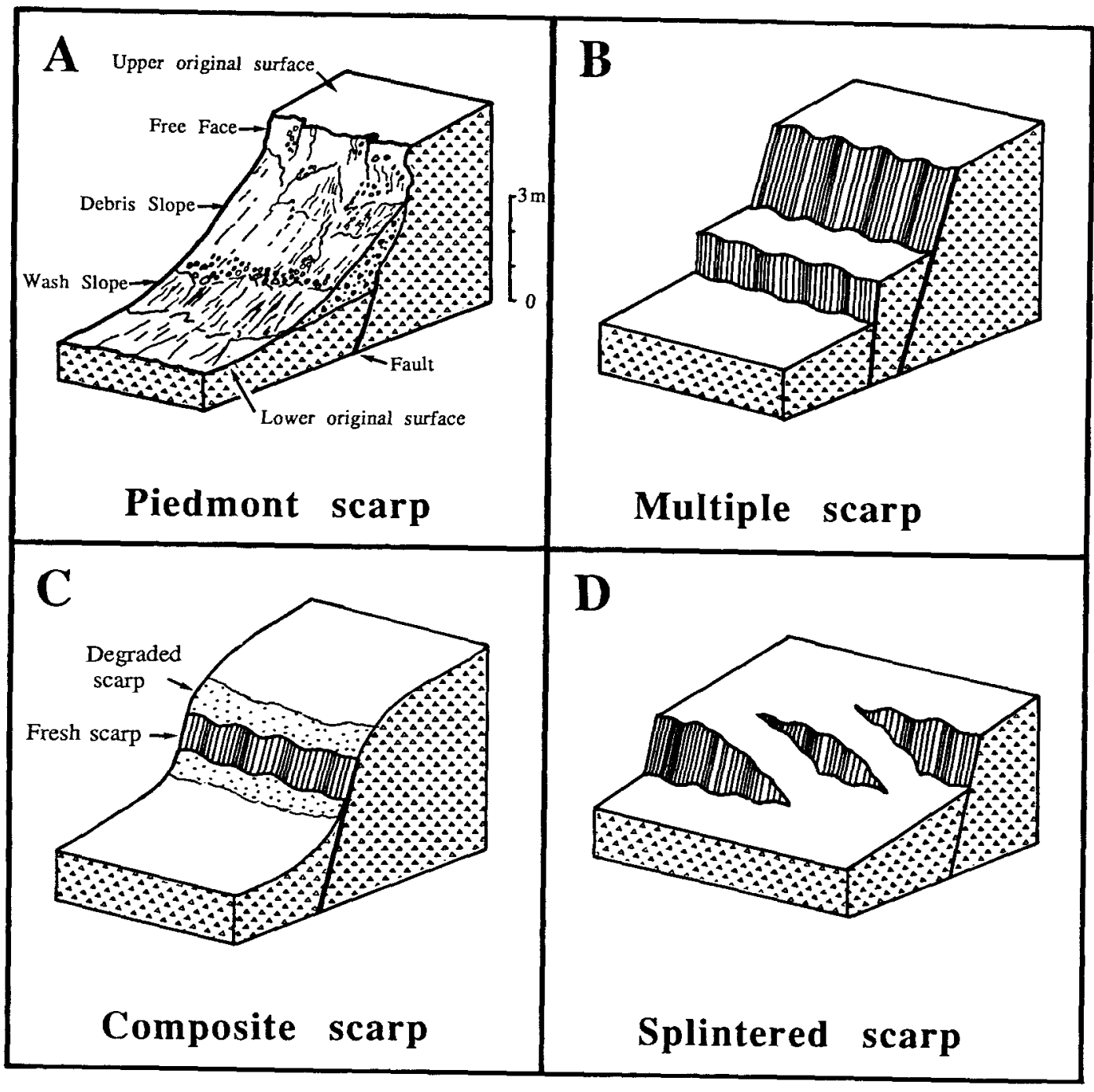

Figure 3. - Varieties of active normal-fault scarps. A, Piedmont scarp developed in unconsolidated material as a result of a single increment of displacement. Simplified from Wallace (1977, fig. 2). B, Multiple scarp related to formation of $a$ fault splay during a single faulting event.
C, Composite scarp related to renewed slip on a fault coincident with an older, degraded scarp. D, Splintered scarp formed as a result of fault displacement being distributed across overlapping en échelon segments. 


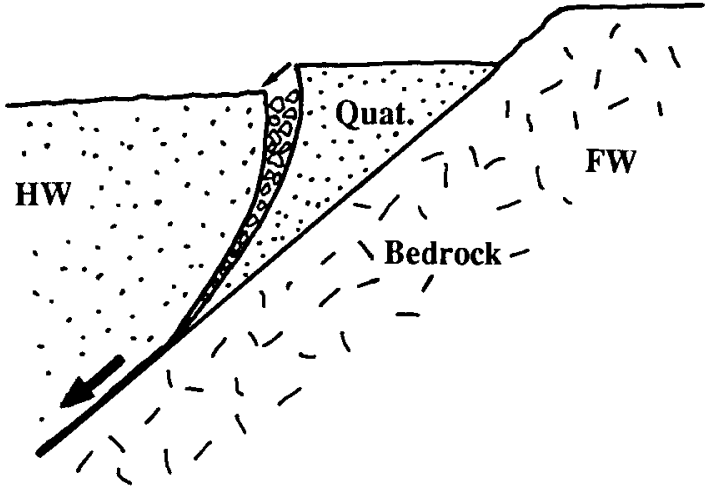

Figure 4.-Near-surface steepening of an upward-propagating normal fault that resulted in an apparent reverse-fault scarp. The opening vector (small arrow) records the same sense of fault motion (extension) as occurs on the main fault at depth (large arrow). Abbreviations: $\mathrm{FW}$, footwall; $\mathrm{HW}$, hanging wall; Quat., Quaternary sediments. Redrawn from Mercier and others (1983, fig. 6a).

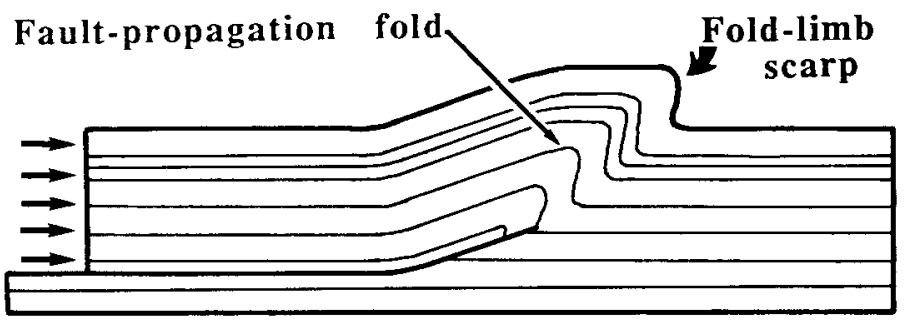

Figure 5.-Development of a fold-limb scarp as the surface expression of a fault-propagation fold related to a thrust at depth. Redrawn from Stein and Yeats (1989, fig. 4).
It is important to discriminate between the scarp form that is produced by faulting and the surface along which movement took place, that is, the fault plane. On bedrock scarps, tectonic lineations etched onto the fault plane may be preserved for long periods (say $10^{5}$ years), which indicates that, despite lengthy exposure, the scarp face represents the original surface of fault movement. By contrast, comparable phenomena are rarely preserved on fault scarps cutting poorly consolidated Quaternary sediments. Along the San Andreas fault in California, USA, laterally discontinuous scarplets that vary in height and are commonly "scissored" (that is, alternate in their direction of facing along strike) are the products of the most recent increment of slip. In contrast, a more continuous topographic ridge coincident with the fault trace is the product of lateral bulging related to long-term fault motion (fig. 7C) (Sieh and Wallace, 1987).

\section{Geomorphic modification of fault scarps}

Although early workers such as Davis (1903) argued that a scarp originally created by faulting should continue to be classed as a fault scarp regardless of the extent to which it is modified by erosion, such an attitude is generally considered impractical. In the western USA, for example, it has long been recognized that mature fault scarps and some erosional scarps (for example, wave-cut scarps and fluvial-terrace scarps) are indistinguishable from one another, and this makes the origin of a degraded scarp difficult or impossible to determine. In addition, many scarps possess both tectonic and erosional elements. A faultline scarp, for example, is ". . . an erosion scarp occupying the line of the original fault and owing its existence merely to the fact that the rocks on one side of the fracture are more resistant than those on the other" (King, 1963, p. 183). Where erosion preserves the sense of relief created by the original faulting, the resulting faultine scarp is said to be consequent, whereas if erosion imposes an opposite sense of relief, it is termed obsequent.

Rockwell and Keller (1984, p. 219) proposed the term "degraded fault scarp" to describe relatively young fault scarps that have been "significantly modified" by erosion, but this term is misleading in that all scarps are degraded to some degree. Instead, we prefer the term "residual fault scarp," a name introduced by Tricart (1974), to describe all scarps from which the last remnants of the original tectonic surface have been removed. In a scheme proposed by Wallace (1977) after the

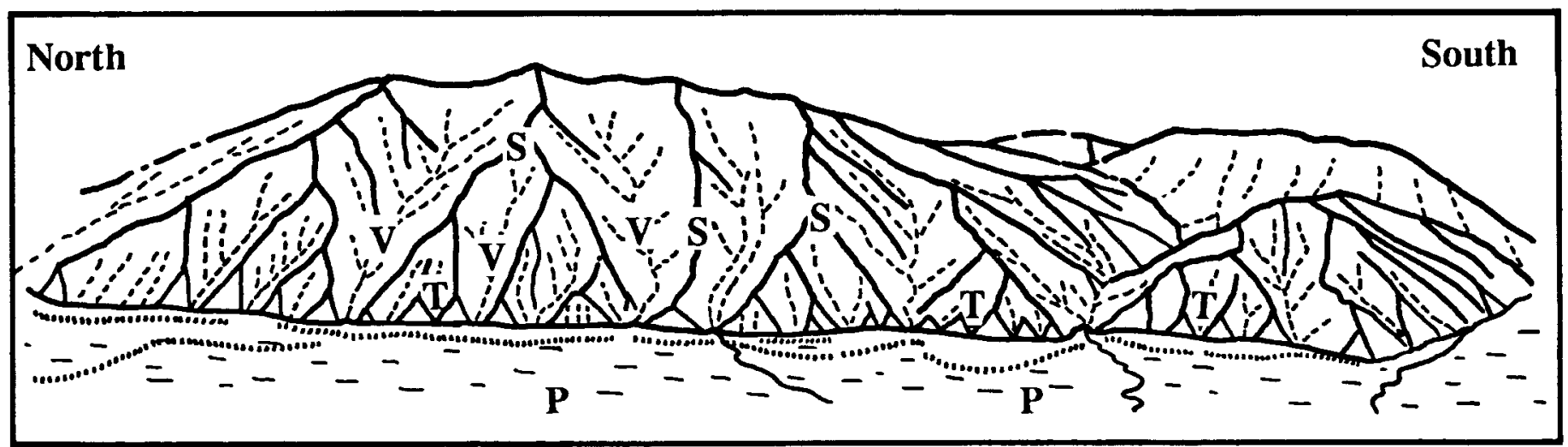

Figure 6. - Spanish Fork Peak area of the Wasatch front, Utah, USA, highlighting the main morphological characteristics of tectonically active range fronts in the Basin and Range province. Stream dissection has divided the range front into alternating transverse spurs (S) and narrow, V-shaped valleys (V). The spurs are associated with well-developed triangular facets $(T)$ at the junction between the mountain front and the piedmont $(P)$. Fault scarps cutting the Quaternary sediments of the piedmont at the base of the range (vertical dashes) attest to the active tectonism of the range front. Taken from Anderson (1977, fig. 17). 
A

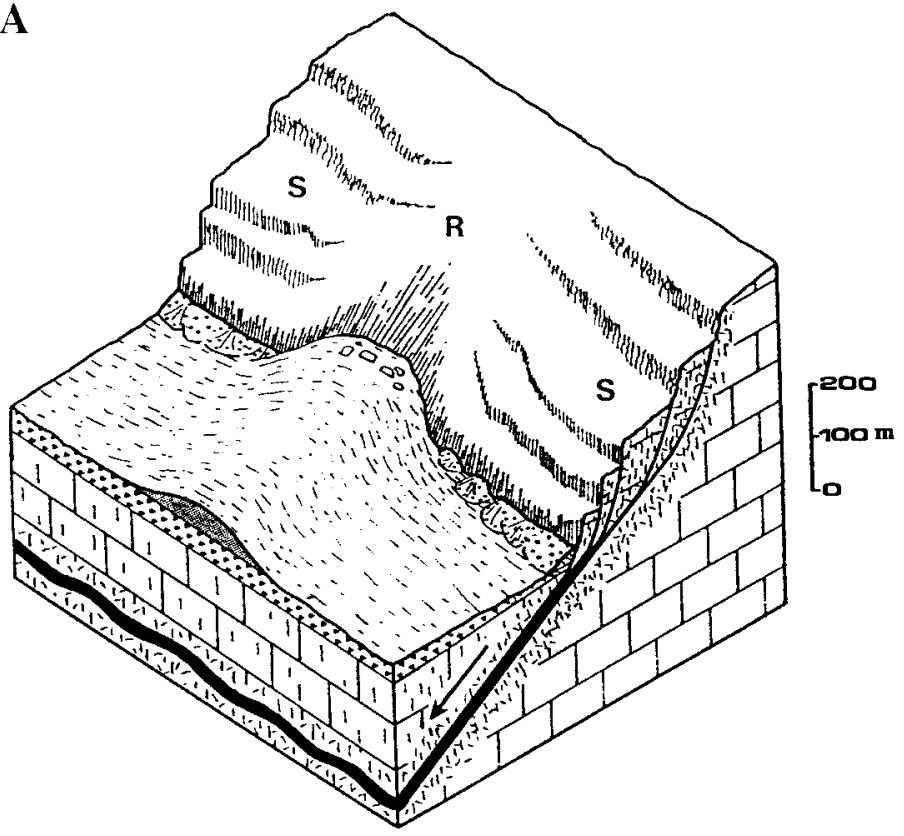

B

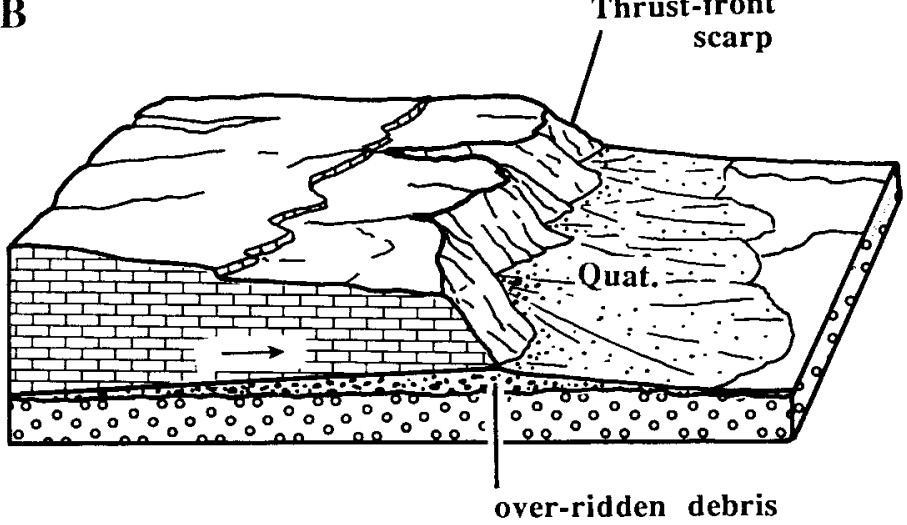

$\mathbf{C}$

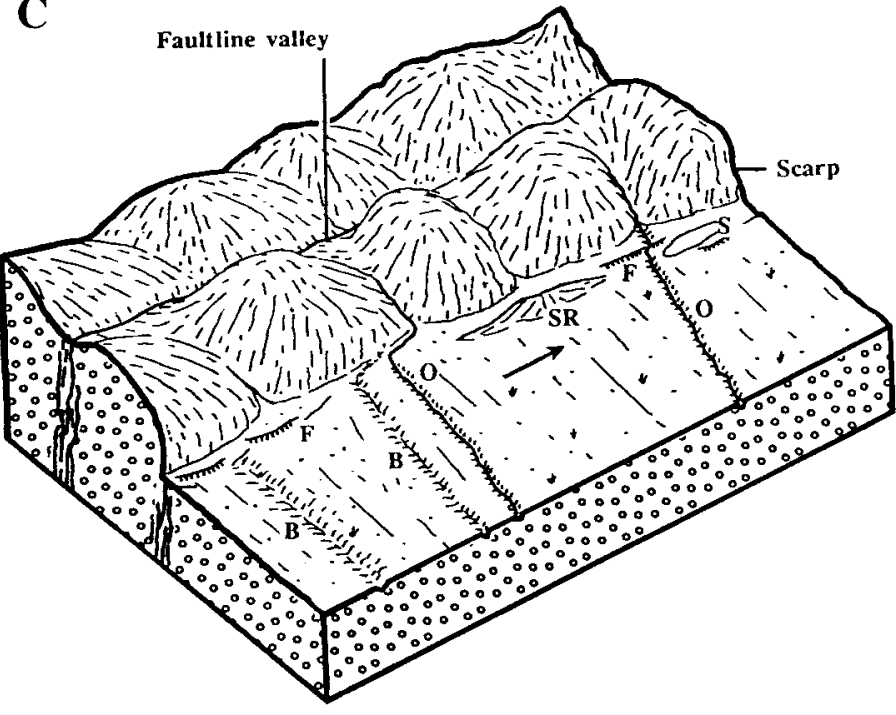

Figure 7.-A, Aegean-type range front showing both steplike $(S)$ and ramplike $(R)$ morphologies. Taken from Stewart and Hancock (1991, fig. 10). B, Topographic expression of a thrustfront scarp. Abbreviation: Quat., Quaternary sediments. Redrawn from Ramsey and Huber (1987, fig. 23.51). C, Selected geomorphic features associated with an active strikeslip fault. Abbreviations: $S$, sag pond; $S R$, shutter ridge; $F$, fault scarp; $B$, beheaded channel; $O$, offset channel. Modified from Sieh and Wallace (1987, fig. 3). creation of a fresh piedmont scarp (fig. 8A), debris falling from the free face results in the rapid retreat of the scarp face and the progressive buildup of a debris slope (fig. $8 \mathrm{~B}$ ). After a period of $10^{1}-10^{2}$ vears, the free face is completely buried by the debris slope, the scarp becomes rounded, and its maximum slope angle decreases (fig. 8C). This "scarp decline" results in the scarp profile being dominated initially by a debris slope (fig. 8D) but later by a wash slope (fig. 8E). Thus, the change from a fault scarp to a residual fault scarp in a piedmont setting occurs when the free face becomes completely buried. In bedrock fault scarps. the removal by denudation of tectonic lineations on the fault-scarp surface would be diagnostic of a residual morphology.

The rate at which a fault scarp degrades is influenced by several lactors. The most important of these, lithology, is discussed in the following section, but other controls also are significant. Topography has an important influence on fault-scarp degradation, as scarps crossing ridges generally are better preserved than scarps on midslopes or along river channels (Yuming, 1989). In addition, the dip of the ground surface before faulting will greatly affect the preservation potential of a scarp, because scarps that slope in the direction of the ground surface before faulting are generally more degraded than scarps that face against the preexisting slope. Microclimatic differences, such as variations in slope aspect, also have a large effect on degradation rates. For example, Pierce and Colman (1986) demonstrated that south-facing scarps in central Idaho, USA, degrade three times as fast as north-facing scarps. They also showed that this disparity in degradation rates became intensified as scarp height increased.

\section{Bedrock fault scarps}

B ecause fault scarps in consolidated materials are less susceptible to denudation than those in poorly consolidated sediments, their preservation potential is greater. Thus, they are capable of describing longer, if more approximate, records of tectonic activity (Mayer, 1986). The importance of lithology in determining the initial morphology of a scarp and in controlling its subsequent response to erosion has been recognized by many workers, and as a result, bedrock scarps are commonly regarded as unsuitable for the standard morphologic dating that is used for poorly consolidated sediments (Mayer, 1984). Despite this, some workers have argued that small bedrock scarps, and even fault-generated range fronts, degrade in the same way as piedmont scarps. Wallace (1977, p. 1272) contended that, although bedrock scarps are characterized by slower rates of change, ". . a after $1 \mathrm{~m} . \mathrm{y}$. 
almost all scarps, even those in bedrock, have declined substantially in slope angle so that other processes are dominant" (fig. 9). Yuming (1989) showed that scarps recently formed in gneisses and schists were subject to slope decline at the rate of $0.036 \% \mathrm{yr}$

It is doubtful, however, whether the Wallace-type model of faultscarp degradation can be applied to all bedrock fault scarps. In particular, faulting in bedrock is accompanied by deformation processes such as fracturing and brecciation, which can modify the lithological properties of the bedrock and, therefore, its susceptibility to erosion. Furthermore, these modifications ". . . may work in either direction; erosion may be facilitated, or it may be hindered according to the circumstances" (Tricart, 1974, p. 235). Of particular importance is the formation of fault rocks of contrasting resistance to erosion in belts that parallel the fault zone and, hence, the fault scarp. Previous models of bedrock-scarp evolution have considered only the effect of subhorizontal sedimentary layers of indurated or weak rock that subtend a high angle with a scarp.

An example of fault rocks that occur in belts that parallel the fault zone is described by Stewart and Hancock (1988) from the Aegean region, where normal-fault scarps in bedrock carbonates (here called Aegean-type fault scarps) are underlain by several belts and sheets of fault breccia of contrasting origin and varying resistance to denudation. Centimeter-thick sheets of well-cemented microbreccia, called compact breccia, immediately underlie fault planes and form armored carapaces on scarps. Underlying compact-breccia sheets are meterwide belts of closely fractured and disaggregated coarse breccias, called incohesive breccias. The presence of multiple fault planes beneath most Aegean-type fault scarps gives rise to a layered architecture of alternating compact-breccia sheets and incohesive-breccia belts (fig. 10A). An additional complication arises because fault-scarp faces are rarely planar surfaces but are corrugated, individual corrugations being several meters wide, tens of meters long, and oriented parallel to the principal direction of slip. Superimposed upon corrugated fault surfaces are a range of small-scale tectonic cavities and fractures that breach compact-breccia carapaces. Thus, the underlying incohesivebreccia belts are exposed to erosion (fig. 10A). The resulting pattern of degradation is uneven, denudation being concentrated at sites of enhanced weathering (fig. 10B). With time, many Aegean-type fault scarps develop a cavitated appearance (fig. 10C). When compactbreccia carapaces have been eroded completely, no further traces of the original scarp remain, and a residual, ragged morphology prevails (fig. 10D).

The pattern of degradation characterizing normal-fault scarps in carbonate bedrock in the Aegean region contrasts in two important aspects with the pattern described from the western USA. Firstly, the morphology of Aegean-type fault scarps is controlled mainly by structural heterogeneity rather than geomorphic activity. Secondly, Aegeantype fault scarps do not progress through a systematic and predictable sequence of morphologic change such as that exhibited by piedmont scarps in the western USA. Together, these attributes mean that, for Aegean-type fault scarps, it is not possible ". . . to relate the change in morphology to the aging or degradation process" as Wallace (1977, p. 1267) proposed for piedmont scarps. Instead, we suggest that morphologic dating of Aegean-type fault scarps should employ alternative criteria to quantify the degree of geomorphic modification. For example, in order to estimate the age of the 1915 Pleasant Valley (Nevada, USA) magnitude 7.2 earthquake, Wallace (1984) used the degree of solution pitting and lichen colonization in limestones on a section of fault plane immediately above the exposed fault plane. Here, we also suggest that the range of fault-plane phenomena ornamenting a scarp face is a useful guide to the age of a bedrock scarp. The fine pedogenic veneer staining many recently activated limestone fault planes is known to be preserved for only a few decades (Wallace, 1984; Blumetti and others, 1988), whereas features such as frictional-wear striae are preserved for considerably longer. Large-scale lineations, such as corrugations, are likely to possess the longest survival times.

\section{Conclusions}

Fault scarps include a diverse range of tectonic landforms that need to be distinguished from one another. Contrasting tectonic styles and degradational processes can lead to scarps of similar appearance, and hence, careful tectonic and geomorphic investigation is required before fault-generated landforms can be used to date faulting events. In particular, we suggest that the term "residual fault scarp" be introduced

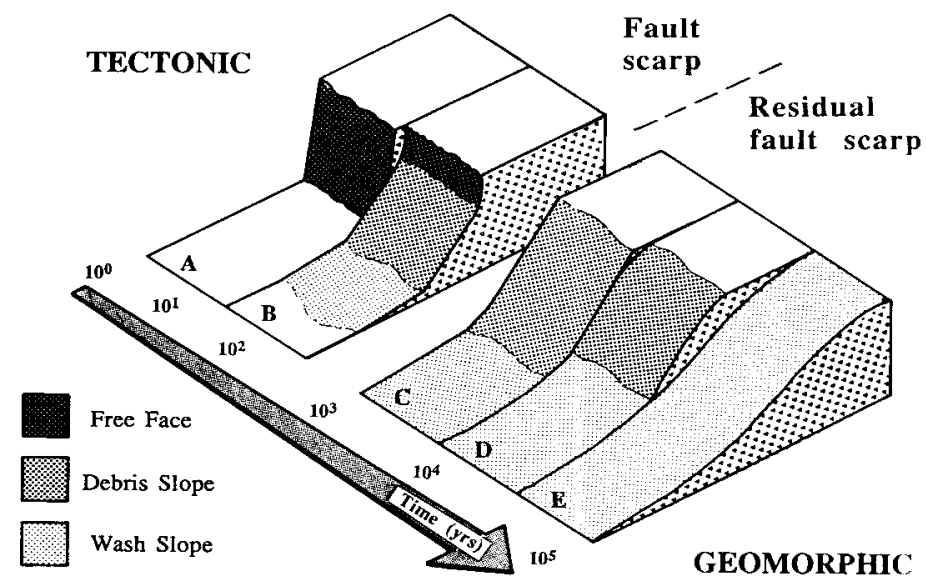

Figure 8.-Modification of a piedmont fault scarp to a residual fault scarp, one that is indistinguishable from an erosional scarp. See text for details. Modified from Wallace (1977, fig. 6).

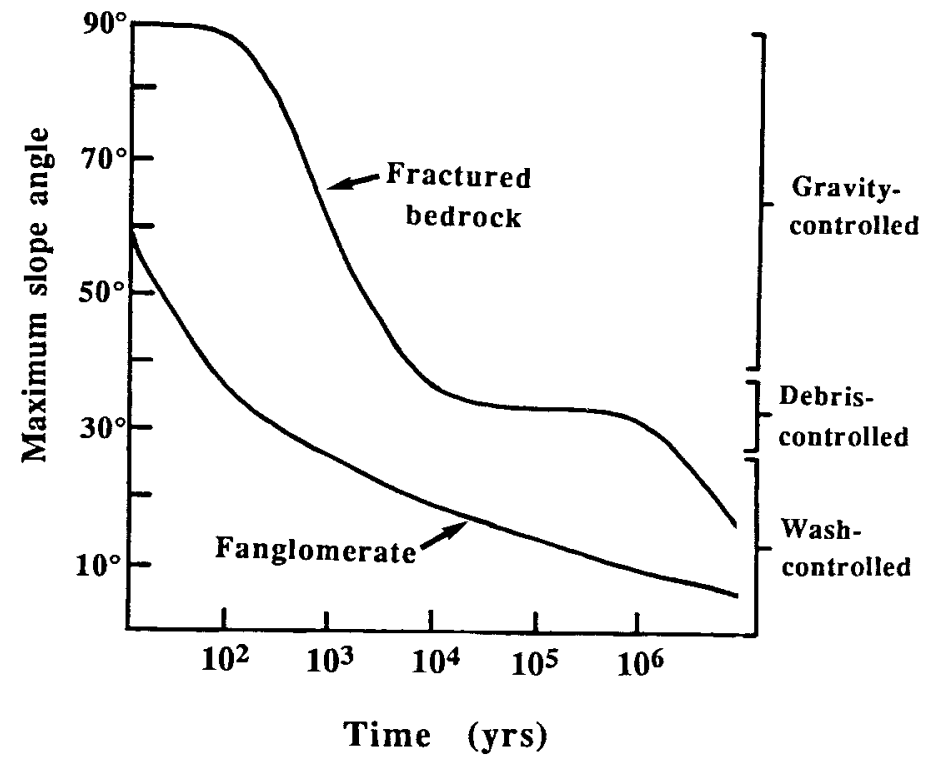

Figure 9.-Limits of maximum slope angle versus age of fault scarp showing that, although scarps in fractured bedrock are modified more slowly than scarps in fanglomerate, bedrock scarps follow a similar sequence of gravity-controlled, debris-controlled, and wash-controlled stages, as well as decreasing slope angle with time. Redrawn from Wallace (1977, fig. 12). 

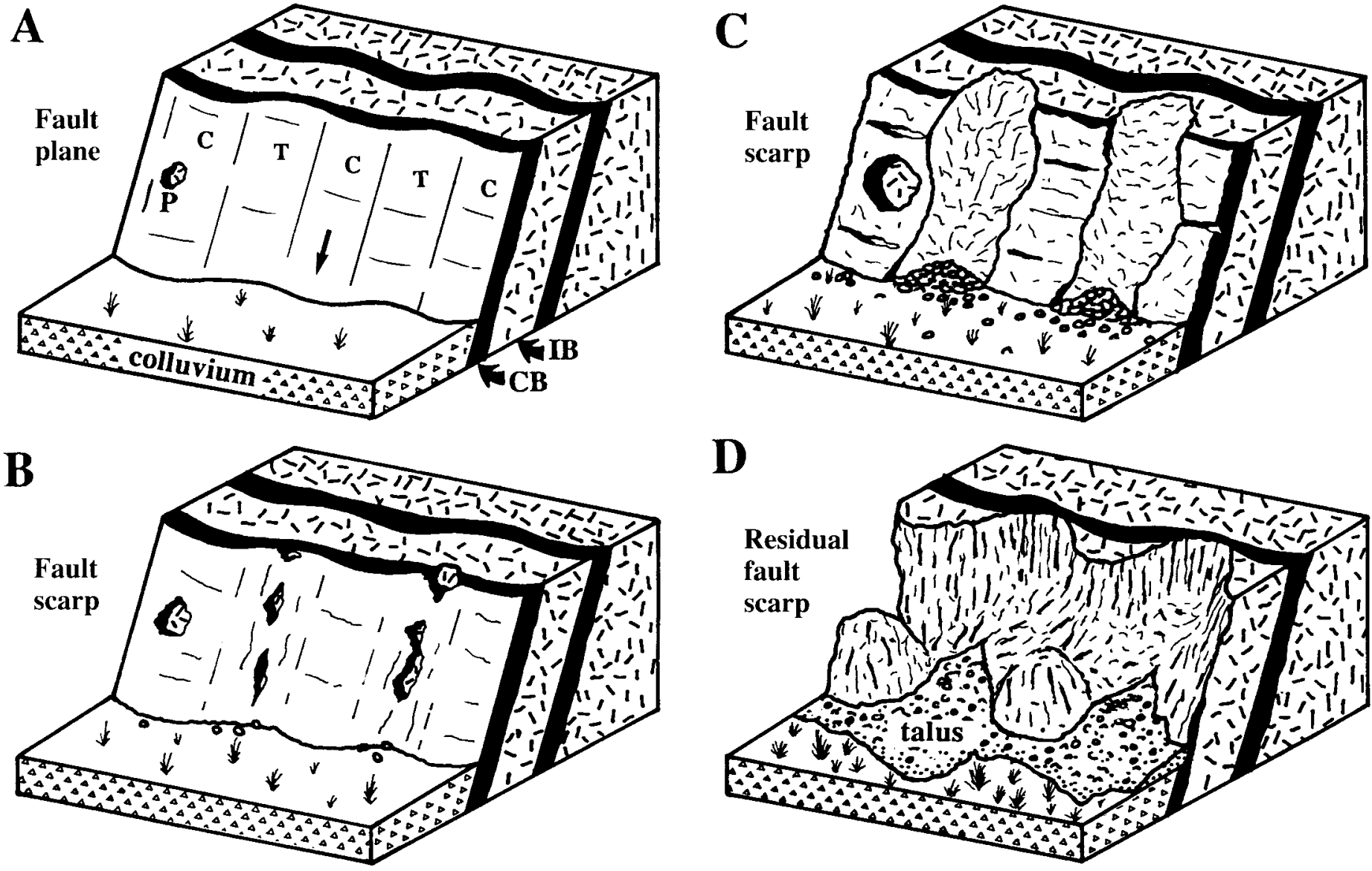

Figure 10.-Pattern of degradation exhibited by normal-fault scarps in carbonate bedrock in the Aegean region. A, A newly emergent and corrugated fault plane cut by tectonic cavities, such as pluck holes $(P)$, and fractures and underlain by alternating layers of compact breccia $(C B)$ and incohesive breccia $(I B)$. B,

10 describe mature fault scarps from which the last remnants of the original tectonic surface have been removed by geomorphic modification. In addition, bedrock fault scarps can exhibit important morphological characteristics related to deformation processes, unlike faults that deform poorly consolidated sediments. In particular, bedrock scarps may be underlain by belts and sheets of fault rocks that parallel the fault zone and are of contrasting resistance to erosion. This layering results in a highly variable pattern of degradation. Although such bedrock scarps are unlikely to be amenable to morphologic dating techniques developed for scarps in poorly consolidated sediments, assessment of the degree of degradation of these bedrock scarps may provide a crude but useful guide to their relative ages.

\section{Acknowledgments}

Our interest in fault-generated landforms was much stimulated by our close involvement in both the International Geological Correlation Programme's Project 206, "Comparison of Major Active Faults," and the Subcommission on Tectonic Nomenclature (part of the International Union of Geological Sciences' Commission on Tectonics). The Royal Society, the National Environment Research Council, and the University of Bristol (UK) funded our fieldwork and attendance at meetings.
Localized breaching of the armored compact-breccia carapace occurs at sites of enhanced weathering. C, Uneven degradation creates a cavitated scarp. D, A residual ragged and embayed fault scarp forms following the removal of the uppermost compactbreccia sheet.

\section{References}

Anderson, T.C., 1977, Compound faceted spurs and recurrent movement in the Wasatch fault zone, north-central Utah: Brigham Young University Geology Studies, v. 24, p. 83-101

Blumetti, A.M., Michetti, A.M., and Serva, L., 1988. The ground effects of the Fucino earthquake of January 13th, 1985; an attempt for the understanding of the recent geological evolution of some tectonic structures, in Margottini, C., and Serva, L., eds., Workshop on historical seismicity of the central-eastern Mediterranean region, Rome, October 27-29, 1987, Proceedings: Rome, Italian Commission for Nuclear and Alternative Energy Sources (ENEA) and International Atomic Energy Agency, p. 297--320.

Bucknam, R.C., and Anderson, R.E.. 1979, Estimation of fault-scarp ages from a scarp-height-slope-angle relationship: Geology, v. 7, p. 11-14

Bull, W.B., and McFadden, L.D., 1977, Tectonic geomorphology north and south of the Garlock fault, California, in Doehring, D.O., ed., Geomorphology in Arid Regions, Binghamton, New York, USA, 1977: Binghamton Symposia in Geomorphology International Series, v. 8, p. $115-138$.

Cotton, C.A., 1949, Geomorphology (5th edition): Auckland, Whitcombe and Tombs Ltd., $505 \mathrm{p}$.

1950, Tectonic scarps and fault valleys: Geological Society of America Bulletin, v. 61, p. 717-758 
Crone, A.J., and Haller, K.M., 1991, Segmentation and the coseismic behaviour of Basin-and-Range normal faults: Examples from east-central Idaho and southwestern Montana, USA: Journal of Structural Geology, v. 13 , p. $151-164$.

Crone, A.J., Machette, M.N., Bonilla, M.G., Lienkaemper, J.T., Pierce, K.L., Scott, W.E., and Bucknam, R.E., 1987, Surface faulting accompanying the Borah Peak earthquake and segmentation of the Lost River Fault, central Idaho: Seismological Society of America Bulletin, v. 77, p. 739-770.

Davis, W.M., 1903, The mountain ranges of the Great Basin: Harvard University Museum of Comparative Zoology Bulletin, v. 42, p. 129-177.

Gilbert, G.K., 1928, Studies of Basin Range structure: U.S. Geological Survey Professional Paper 153, $92 \mathrm{p}$.

Gordon, F.R., 1971, Faulting during the earthquake at Meckering, Western Australia, 14 October 1968: Royal Society of New Zealand Bulletin, v. 9 , p. $95-96$.

Hamblin, W.K., 1976, Patterns of displacement along the Wasatch fault: Geology, v. 4, p. 619-622.

Hancock, P.L., 1988, Neotectonics: Geology Today, v. 4, p. 57-61.

Hancock, P.L., and Barka, A.A., 1987, Kinematic indicators on active normal faults in western Turkey: Journal of Structural Geology, v. 9, p. $573-584$.

King, G.C.P., and Vita-Finzi, C., 1981, Active folding in the Algerian earthquake of 10 October 1980; Nature (London), v. 292, p. 22-28.

King, L.C., 1963, South African scenery (3rd edition): London, Oliver and Boyd, 308 p.

McCalpin, J., 1987, Geologic criteria for recognition of individual paleoseismic events in extensional environments, in Crone, A.J., and Omdahl, E.M., eds., Directions in paleoseismology: U.S. Geological Survey Open-File Report 87-673, p. 102-114.

Matsuda, T., Imaizumi, T., and Nakata, T., 1989, Near-surface features of a thrust fault moved at the time of the 1896 Riku-u earthquake in Japan, revealed by excavation, in Worldwide Comparison of Characteristics of Major Faults, Mammoth Lakes, California, USA, July 2-4, 1989, Abstracts: International Geological Correlation Programme Project 206 meeting.

Mayer, L., 1984, Dating Quaternary fault scarps formed in alluvium using morphologic parameters: Quaternary Research, v. 22, p. 300-313.

1986. Tectonic geomorphology of escarpments and mountain fronts, in Wallace, R.E., chairman. Active tectonics, in the collection Studies in geophysics: Washington, D.C., National Academy Press, p. 125-135.

Mercier, J.L., Carey-Gailhardis, E., Mouyaris, N., Simeakis, K., Roundoyannis, T., and Anghelidhis, C., 1983, Structural analysis of recent and active faults and regional state of stress in the epicentral area of the 1978 Thessaloniki earthquakes (northern Greece): Tectonics, v. 2 , p. $577-600$.

Nash, D., 1986, Morphologic dating and modeling degradation of fault scarps, in Wallace, R.E., chairman, Active tectonics, in the collection Studies in geophysics: Washington, D.C., National Academy Press. p. 181-194.

Petersen, J.F., 1985, Equilibrium tendency in piedmont scarp denudation, Wasatch Front, Utah, in Morisawa, M., and Hack, J.T., eds., Tectonic Geomorphology, Binghamton, New York, USA, 1984: Binghamton Symposia in Geomorphology International Series, v. 15, p. 209-233.

Philip, H., and Meghraoui, M., 1983, Structural analysis and interpretation of the surface deformation of the El Asnam earthquake of October 10, 1980: Tectonics, v. 2, p. 17-49.

Pierce, K.L., and Colman, S.M., 1986, Effect of height and orientation (microclimate) on geomorphic degradation rates and processes, lateglacial terrace scarps in central Idaho: Geological Society of America Bulletin, v. 97, p. 869-885.

Ramsay, J.G., and Huber, M.J., 1987, Folds and fractures, v. 2 of Modern structural geology: London, Academic Press, $700 \mathrm{p}$.
Rockwell, T.K., and Keller, E.A., 1984, Tectonic geomorphology, Quaternary chronology and palaeoseismology, in Costa, J.E., and Fleisher, P.J., eds., Developments and applications of geomorphology: Berlin, Springer-Verlag, p. 203-239.

Sieh, K., and Wallace, R.E., 1987, The San Andreas fault at Wallace Creek. San Luis Obispo County, California: Geological Society of America Centennial Field Guide, Cordilleran section, p. 233-238.

Stein, R., and Yeats, R., 1989, Hidden earthquakes: Scientific American, v. 260 , p. $48-57$.

Stewart, I.S., and Hancock, P.L., 1988, Fault zone evolution and fault scarp degradation in the Aegean region: Basin Research, v. 1, p. 139-153.

-1991 , Scales of structural heterogeneity within neotectonic normal fault zones in the Aegean region: Journal of Structural Geology, v. 13, p. 191-204.

Thornbury, W.D., 1964, Principles of geomorphology (2nd edition): New York, John Wiley, 594 p.

Tricart, J., 1974, Structural geomorphology: London, Longman Inc., 305 p.

Wallace, R.E., 1977, Profiles and ages of young fault scarps, north-central Nevada: Geological Society of America Bulletin, v. 88, p. 1267-1281.

-1984 . Fault scarps formed during the earthquakes of October 2. 1915, in Pleasant Valley, Nevada, and some tectonic implications: U.S. Geological Survey Professional Paper 1274-A, 33 p.

Yeats, R.S., and Lillie, R.J., 1991, Contemporary tectonics of the Himalayan Front system: Folds, blind thrusts and the 1905 Kangra earthquake: Journal of Structural Geology, v. 13, p. 215-225.

Yuming, Z., 1989, Slope variation and ages of fault scarps and recurrence intervals of great earthquakes on the Koktokay-Ertai fault: Earthquake Research in China, v. 1, p. $377-388$.

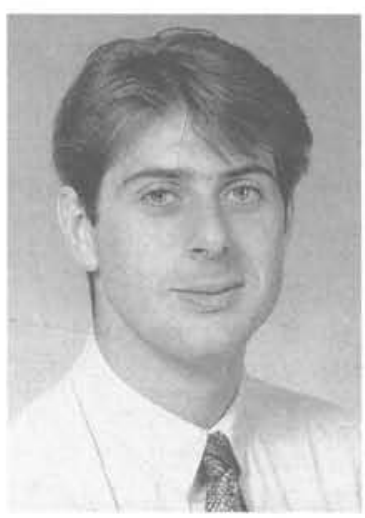

Iain S. Stewart, born in 1964, recently has completed a doctorate at the University of Bristol (UK) on the structural and geomorphic characteristics of neotectonic normal faults in the Aegean region. He is a Lecturer in structural geology at the West London Institute of Higher Education, where his main interests are in tectonic geomorphology.

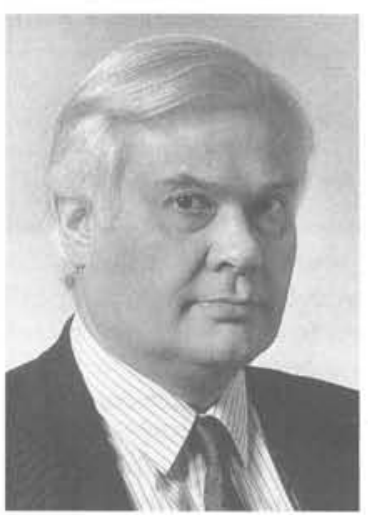

Paul L. Hancock, born in 1937, is a Reader in structural geology at the University of Bristol. In 1979 he founded the Journal of Structural Geology and was its Chief Editor for 8 years. Since 1984, he has been UK correspondent to IGCP Project 206, and in 1989, he became Secretary General to the IUGS Commission on Tectonics while continuing as Chairman of its Subcommission on Tectonic Nomenclature. His current research interests are in neotectonics, especially faulting and jointing. 